\title{
Artificial Intelligence and Machine Learning to Assist Climate Change Monitoring
}

\author{
Rahul Malik $^{1, \mathrm{a}}$, Sagar Pande ${ }^{1, \mathrm{~b}}$, Nishi ${ }^{2, \mathrm{c}}$, Aditya Khamparia ${ }^{1, \mathrm{~d}, *}$ \\ ${ }^{1}$ LOVELY PROFESSIONAL UNIVERSITY, Punjab, India. \\ ${ }^{2}$ DAV UNIVERISTY, Punjab, India. \\ a Rahul.23360@lpu.co.in, ${ }^{\mathrm{b}}$ Sagarpande30@gmail.com, ${ }^{\mathrm{c}}$ nishi.02.bti@gmail.com, ${ }^{\mathrm{d}}$ aditya.khamparia88@gmail.com \\ *Corresponding Author: Aditya Khamparia, Email: aditya.khamparia88@gmail.com
}

How to cite this paper: Rahul Malik, Sagar Pande, Nishi, Aditya Khamparia (2020). Artificial Intelligence and Machine Learning to Assist Climate Change Monitoring. Journal of Artificial Intelligence and Systems, 2, 168-190.

https://doi.org/10.33969/AIS.2020.21011.

Received: March 18, 2020

Accepted: May 11, 2020

Published: May 25, 2020

Copyright ( 2020 by author(s) and Institute of Electronics and Computer. This work is licensed under the Creative Commons Attribution International License (CC BY 4.0).

http://creativecommons.org/licenses/by/4.0/

\begin{abstract}
Climate change issues societal operation, likely wanting considerable adaptation to deal with doing well altered weather patterns. Machine learning (ML) algorithms have progressed considerably, triggering breakthroughs in some other investigation sectors, along with only lately suggested as helping climate evaluation. Though a significant volume of isolated Earth System functions are analyzed with ML techniques, much more generic phone system to find out better the whole temperature unit hasn't happened. For instance, ML is able to aid remote identification, in which complex feedbacks make characterization tough from instantaneous equation analysis or perhaps possibly visualization of sizes plus Earth System design (ESM) diagnostics. Artificial intelligence (AI) may thus build on determined climate associates to provide enhanced alerts of approaching eco-friendly functions, which includes intense events. While ESM development is actually completely necessary, a parallel concentrate on utilizing ML and AI to determine as well as capitalize a great deal more on pre pre-existing simulations as well as info is suggested by us.
\end{abstract}

\section{Keywords}

Climate, glacier retreat, mass balance, lakes, sea level

\section{Introduction}

Ice as well as glacier ice sheet about $10 \%$ of the world's acreage region and also possess 26 million cubic kilometers of ice. Himalayas have among the biggest plethoras of ice as well as glaciers apart from the Polar Regions within the majority of the core Asia, thus conferring it with the name' third pole' of the planet. Ice fields and glaciers together create one of the most basic freshwater assets for the Indian financial climate. Flora and fauna of the Himalayas along with foothills count on the 
molten foot bath of these frigid reservoirs. Furthermore, the Himalayan glaciers conduct the worldwide climate and additionally serve as delicate pointers of environmental reduce. These wellsprings of water are not durable as frosty sizes transformation with the climate. Research are done over the Himalayan icy masses, change in their general vicinity and length, and change in mass parity, ice sheets speed and furthermore on the run from. The climatic effect on the glacier is mirrored by these parameters[1].In particular, we used Tensorflow 2.0 Notebook Instance that has pre-installed Tensorflow with Keras support. It also had all other essential artificial intelligence and machine learning libraries compiled in it. Model was developed using libraries including Tensorflow, Keras, Matplotlib, Numpy, Scipy, etc.

\section{Perception of changes in the climate system}

Perceptions of the atmosphere framework depend on immediate actual physical as well as biogeochemical dimensions, along with remote sensing from ground facilities as well as satellite; info derived from paleoclimate archives offers an extended context. The evaluation of observational proof for climate change is summarized in this area [2].

\subsection{Transformation in Temperature}

It's positive globally balance area heat (GMST) has grown after the late 19th centenary (Figure 1). Many of the previous three years is successively hotter at the Planet's surface area than any the previous years in the key shoot, as well as definitely the decade of 2000's is still possibly the warmest [3]. The worldwide found the middle value of joined land just as sea temperature records as determined by a straight trend 5 , unmistakably show a warm up of $0.85{ }^{\circ} \mathrm{C}$, over the duration 1880 to 2012, when a couple autonomously made datasets are existing, around $0.89^{\circ} \mathrm{C}$ over the duration 1901 to 2012 , alongside $0.72{ }^{\circ} \mathrm{C}$ over the period 1951 to 2012 when grounded on three freely created data sets. The entire extension between the standard of the 1850 to 1900 minute and the 2003 to 2012 timeframe is $0.78{ }^{\circ} \mathrm{C}$ dependent on the Hadley Center/Climatic Research Unit gridded surface warmth information set 4 (HadCRUT4), the worldwide mean surface area temperature dataset together with the longest history of the three autonomously delivered informational collections [4].

\subsection{Maintaining the Integrity of the Specifications}

The globe is in radioactive asymmetry, with further straightforward daylight entering than leaving the highest point of the environment, after at least approximately 1970. It is almost sure the Earth has procured significant vitality from 1971 to 2010. The determined improved vitality stock between 1971 additionally as 2010 is 274 [196 to 351]x1021 J (high certainty), with a warming speed of $213 \times 1012 \mathrm{~W}$ starting from a direct fit on the yearly qualities over that particular timeframe [5]. Sea warming overwhelms that total warming rate, with complete marine sum warming representing approximately $903 \%$ (high certainty), and furthermore warming of top of the (zero to $700 \mathrm{~m}$ ) coastline representing approximately $604 \%$ softening ice (Including Arctic ocean ice, ice sheets notwithstanding icy masses), and furthermore warming of the landmasses each record for $3 \%$ of the aggregate. The other $1 \%$ is remunerated by warming on the 
planet. The 1971 to 2010 determined pace of marine power gain is $199 \times 1012 \mathrm{~W}$ beginning from a direct fit to subtleties over that timeframe, proportionate to 0.42 $W^{2}$ heating utilized ceaselessly over the Earth's all out surface, and furthermore $0.55 \mathrm{Wm}^{2}$ part attributable to sea warm up utilized up the sea' s complete outer region zone. The Earth's accepted vitality increment from 1993 to 2010 is 163 [127 to 201] x1021 J and have a course assessment of $275^{*} 1015 \mathrm{~W}$, the marine piece of the plan for 19932010 is $257 \times 1012 \mathrm{~W}$, identical to a mean warmth motion to the sea of $0.71 \mathrm{Wm}^{2}[6]$.

The mean of all India yearly warmth has grown by $0.05^{\circ} \mathrm{C}$ every single ten year from 1901 2003, and also in the latest 3 years, the mean yearly warmth has grown by $0.22{ }^{\circ} \mathrm{C}$ every ten year, marking a sizable speed of the warm up trends in the latest time [7]. Based on the IPCC Fifth Assessments accounts on consolidated worldwide ocean and land temperature data, there's increase of approximately $0.89{ }^{\circ} \mathrm{C}$ (0.69 0.89) over the period 19512012 [8]. During the final 4 years loss in glacial ice continues to be approximated as $19 \pm 7 \mathrm{~m}$. This insights loss of $443 \pm 136 \mathrm{Gt}$ of ice mass from a total 36004400 Gt of icy spared ordinary waters in the Himalaya. These examinations have what's more demonstrated that propose misfortune in icy mass inside the Himalaya Is really rushed sort $-9 \pm 4$ to $-20 \pm 4$ Gy/years between the periods 1975 to 85 and 2000to 2010. Thus, it could be realized that: Ocean heat instigated thermal extension of ocean waters, thus sea elevation rises [9].

\subsection{Drivers of climate change}

Individual movements have been changed and carry on and alter the Earth's exterior and surface and atmosphere distribution. Several of these improvements has an indirect or direct effect on the power harmony of the Earth and therefore motorists of temperature chan. Radiative forcing or climate forcing is the difference between insolation (sunlight) absorbed by the Earth and energy radiated back to space. Changes to Earth's radiative equilibrium, that cause temperatures to rise or fall over decadal periods, are called climate forcing's. Radiative forcing is conveyed in watts per square meter $\left(\mathrm{W} \mathrm{m}^{2}\right)$ Anthropogenic pollutants[10] have pushed the modification in all around blended ozone depleting substance (WMGHG) sums during the Industrial Era it is sure expanding environmental weights of countless WMGHGs, particularly CO2, resulted in a supplemental expansion of the RF from 2005 to 2011. According to concentrate modifications, the RF of most WMGHGs 2011 is 2.83 [2.54 to 3.12] W m².This's a rise because AR4 of 0.20 [0.18 to 0.22 ] W $\mathrm{m}^{2}$, with almost all of the expansion as a result of the increased the abundance of CO2 by itself is 1.82 [1.63 to 2.01$] \mathrm{W} \mathrm{m}^{2}$.

After a decade of near balance, the latest expansion of $\mathrm{CH} 4$ focus resulted in an increase RF as opposed to AR4 by two \% to 0.48 [0.43 to 0.53 ] $\mathrm{Wm}^{2}$. Atmospheric $\mathrm{N} 2 \mathrm{O}$ has grown by six \% since AR4, creating an RF of 0.17 [0.14 to 0.20$] \mathrm{Wm}^{2}$. The short lived GHGs ozone (Stratospheric water and O3) vapour in addition help with anthropogenic forcing. Observation points that $\mathrm{O} 3$ very expanded at numerous undisturbed place through the 1990s. These boosts have gone on primarily over Asia observations deal with a restricted area and then depressed over Europe during the

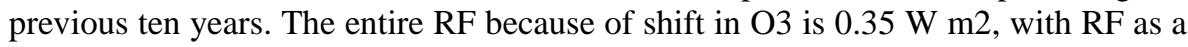
result of tropospheric $\mathrm{O}_{3}$ of $-0.05 \mathrm{Wm} 2$ utilizing evidence from some constraints and aerosol model from observations [11]. The RF from dark CO2 on ice and ice is evaluated to be $0.04 \mathrm{wm}^{2}$. There's strong proof that anthropogenic area use 
modifications including deforestation have improved the acreage surface albedo, which results to an RF of $-0.15[-0.25$ to 0.05$] \mathrm{Wm}^{2}$.

Volcanic and solar forcing would be the two dominant natural contributing factors to worldwide climate change during the Industrial Era. Satellite observations of overall sunlight irradiance changes after 1978 shows quasi regular cyclic deviation with numerous about 11 years. Longer term forcing is often approximated by correlation of daylight minima (during what inconstancy is gutter). This gives a RF changes of $-0.04 \mathrm{Wm}_{2}$ betwixt most new (2008) least and unquestionably in the 1986 least [12].
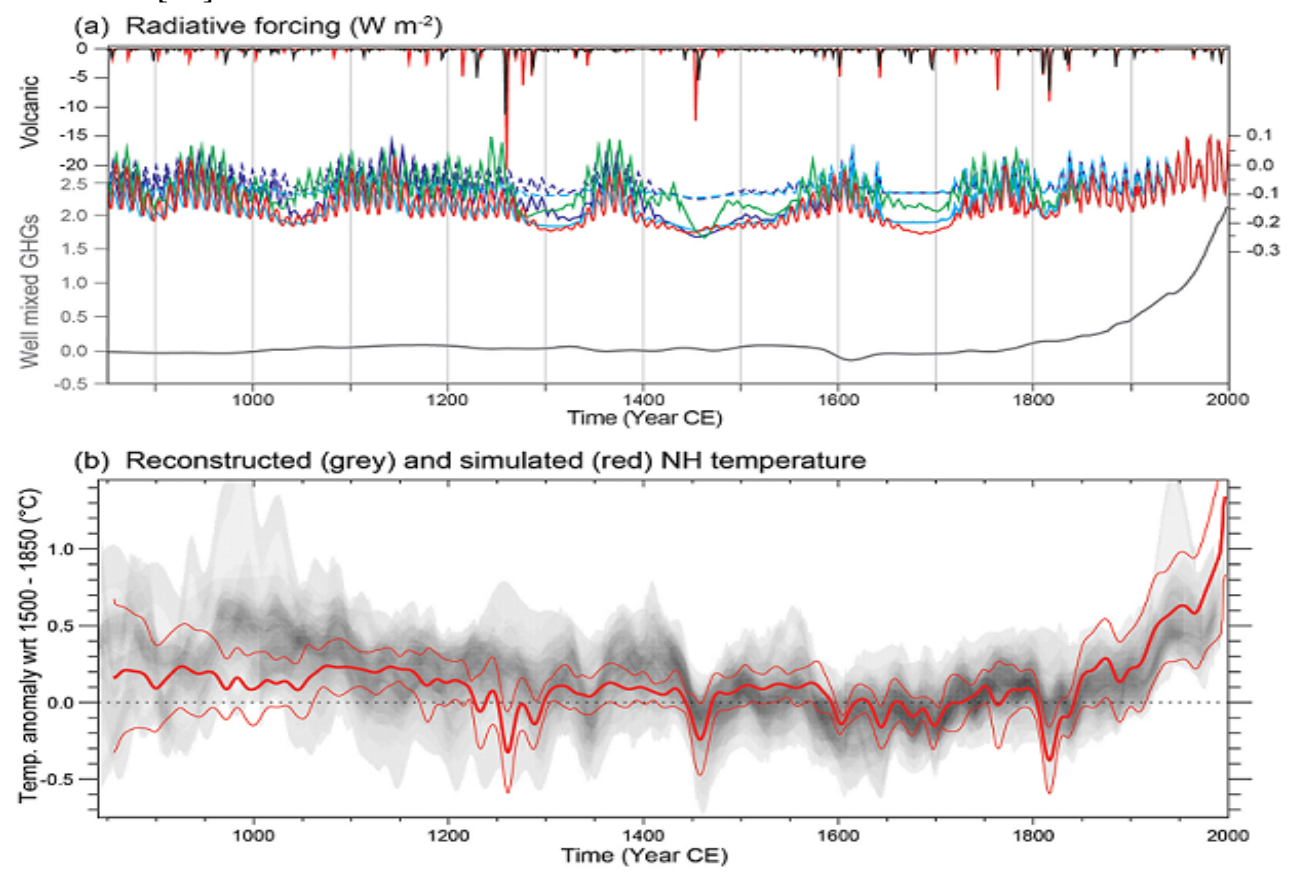

Figure 1. Global Radiative forcing and $\mathrm{NH}$ temperature has increased since the late 19th

\section{Review of Glacier Inventory}

Table 1. Glacier Inventory over Himalayan and Karakoram

\begin{tabular}{|c|c|c|c|c|}
\hline S.No. & Source & Location & No. Of Glacier & Area $\left(\mathrm{Km}^{2}\right)$ \\
\hline 1 & Bolch et al., 2009 & Himalaya and karakoram & - & 40,800 \\
\hline 2 & Kaab et al., 2012 & $\begin{array}{l}\text { Hindu Kush } \\
\text { Karakoram } \\
\text { J and k } \\
\text { H.P., Uttarakhand and west Nepal; East } \\
\text { Nepal and Bhutan }\end{array}$ & $\begin{array}{l}- \\
- \\
- \\
- \\
-\end{array}$ & $\begin{array}{l}9,350 \\
21,750 \\
4,500 \\
14,550 \\
9,550\end{array}$ \\
\hline 3 & Frey et al., 2012 & $\begin{array}{l}\text { Indus (Jhelum, Chenab, shyok, Ravi, } \\
\text { Sutlej, and GorZangbo) and Ganges } \\
\text { (Yamuna, Bhagirati, and Alaknanda) }\end{array}$ & 9,310 & 11,400 \\
\hline 4 & Cogley et al., 2018 & Himalaya and Karakoram & 20,812 & 43,178 \\
\hline 5 & Bajracharya and Shreshta , 2011 & $\begin{array}{l}\text { Hindu kush, Himalaya, Karakoram, } \\
\text { Nepal, Bhutan }\end{array}$ & 15,000 & 33,000 \\
\hline 6 & Cogley et al., 2009 & H.P., Uttarakhand, Nepal, Bhutan and & 12,623 & 28,268 \\
\hline
\end{tabular}


Rahul Malik et al.

\begin{tabular}{|c|c|c|c|c|}
\hline & & Pakistan & & \\
\hline 7 & Ohmura et al., 2009 & India, Pakistan, Bhutan,Nepal, ${ }^{\mathrm{a}} \mathrm{China}^{\mathrm{b}}$ & $\begin{array}{l}6,952 \\
46,377\end{array}$ & $\begin{array}{l}47,500 \\
59,430\end{array}$ \\
\hline 8 & Kaul et al., 1999 & $\begin{array}{l}\text { Indus, Ganga and Brahmaputra basin } \\
\text { (Indian region) }\end{array}$ & 5,243 & 37,959 \\
\hline 9 & Kulkarni et al., 2019 & Indian Himalaya & 1,702 & 23,315 \\
\hline 10 & Sangewar and Shukla, 2009 & Indus, Ganga, and Brahmaputra & 9,040 & 18,528 \\
\hline 11 & A.K. Sharma and Kulkarni, 2013 & Indus, Ganga, and Brahmaputra & 32,392 & 71182.08 \\
\hline 12 & GSI 2019 & Indian Himalaya & 9,573 & 37484 \\
\hline 13 & Fery, 2011 & Himalaya \& Karakoram & 32556 & 57357 \\
\hline 14 & Cogley, 2018 & Himalaya \& Karakoram & 20812 & 43178 \\
\hline 15 & ISRO, 2019 & Himalaya & 32392 & 71180.98 \\
\hline 16 & HighNoon, 2011 & Hindu Kush, Karakoram and Himalaya & 34732 & 50325 \\
\hline 17 & ICIMOD, 2019 & Hindu Kush Himalaya & 54252 & 60054 \\
\hline 18 & J. Bahugana and others, 2014 & $\begin{array}{l}\text { Karakoram, H.P., Zanskar, Uttarakhand, } \\
\text { Nepal. }\end{array}$ & 2018 & 10256.68 \\
\hline
\end{tabular}

A glacier listing is just lately developed by the ISRO for the Indus, Ganges and Brahmaputra bowls on a 1:50 zero degree with LISS III satellite points of interest for time from 2004 to 2007 or more subordinate material. Altogether, 32,392 ice sheets are uncovered, covering a thing of 70 one $182.08 \mathrm{~km}^{2}$ [13]. These sums notice ice sheets arranged inside Outside and India of the Indian domain however inside a bowl seeping out into India. The use of it's for examinations, for instance of watershed wide gauges of ice sheet inclusion are confined by the spatial augmentation of the posting data following administration outskirts alongside hydrological catchments [14]. Hence, figures for pretty much any Brahmaputra bowl, for example, ought not be seen as complete, Isolated by watersheds, the posting outline shows a glaciered spot of the Indus bowl of $302246.43 \mathrm{~km}^{2}(16049$ icy masses), $18392.90 \mathrm{~km}_{2}$ (6 237 ice sheets) in the Ganges bowl alongside 20 $542.75 \mathrm{~km}_{2}$ (10 1006 icy masses) in the Brahmaputra basin [15]. Normal icy mass sizes in Indus, Ganga and Brahmaputra bowls as $2.03 \mathrm{sq}$. km. separately. It infers the ice sheets are of bigger sizes in the Ganga bowls rather than the additional two bowls [16].

Forceful evaluating circulations of the manufacture region, removal region, supra chilly lakes and expert icy or perhaps moraine dammed lakes is more prominent for the four frigid element hand to hand fighting classes in Ganges bowl than mean area in Brahmaputra and Indus bowls. The bit of greater ice sheets is a lot higher in the Ganga bowl. It's been discovered the rate aggregation region might be the top in the Indus bowl as than other two bowls. The bit gathering zone is just about tantamount among Brahmaputra and Ganga bowl. The proportion of development to removal region is stacked with Indus bowl. The proportion of development to removal region is just about practically identical among Brahmaputra and Ganga bowls. This recommends the icy masses on the Indus bowl have greater feed region and furthermore subsequently are nearly considerably steadier instead of the extra two bowls. The \% removal region flotsam and jetsam assurance is just about similar among Brahmaputra and Ganga bowl and is lower in the Indus bowl. The removal district ice uncovered will be the top in Indus bowl [17]. The removal area ice uncovered is just about indistinguishable among Brahmaputra and Ganga bowl. For the Ganga and Brahmaputra bowl, the gathering - removal area extents are very and low of the glaciated areas are encountering different amounts of trash spread. The critical flotsam and jetsam security assumes a significant job by hindering the warmth from sun beams and hence decreasing the 
liquefying of ice sheet ice. In any case, the issue of these icy mass gives is controlled by its height together with latitudinal circulation. The icy lakes, every one supra icy and furthermore genius icy or moraine-dammed lakes are produced using icy mass liquefy water and furthermore the aggregate just as style of these lakes are utilized to comprehend the ice sheet soften significant strategies and examples. The Indus bowl has a littler antagonistic sizes of 0.05 alongside $0.7 \mathrm{~km}^{2}$ for star cold lake and supra ice sheet in contrast with the Ganga bowl 0.17 likewise as $0.33 \mathrm{~km}^{2}$ and unquestionably the Brahmaputra bowl 0.15 just as $0.31 \mathrm{~km}^{2}$ separately.

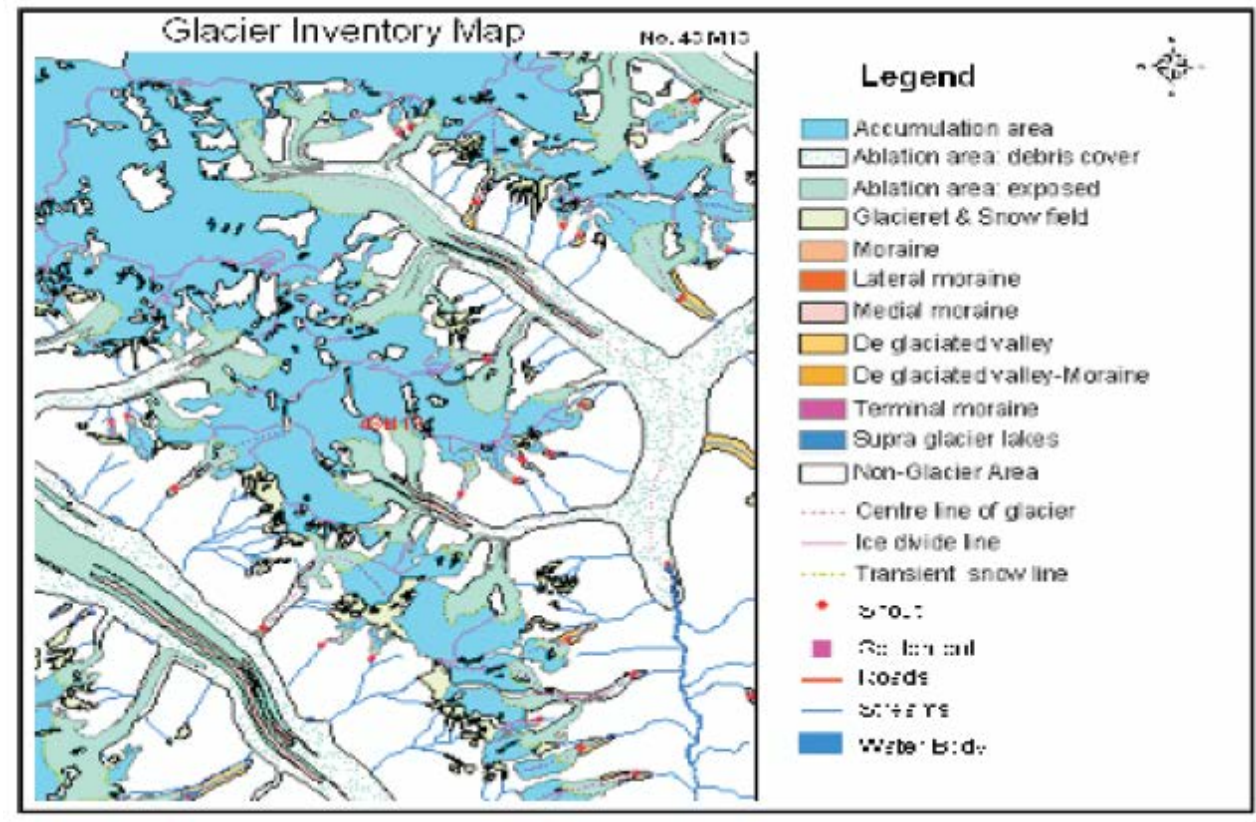

Figure 2. Glacier inventory map[10]

\section{Climate science gaps}

We grow on this, showing an overarching perspective of weather evaluation. Existing programs are reviewed by us, overview ML methods, discuss three possible applications, and also address ways AI will helped society with adjust to climate drastic changes having an emphasis on scarcity. Nevertheless, climate different models differ to the potential position of theirs, GHG level higher trigger point or maybe ESM impacted component impacted. Should formulas considerably different anticipated, the new equation terms might in addition point in presence of unknowns. Some tele-connections have some time offsets, perhaps societal alerts generating of severe weather events approaching. The degree which tele-connections occur for abnormal recently rainfall has just been recognized, mentioned as deserving of substantial extra exploration [45].

ML methods are (semi) robotic methods to info inference which make extremely much less or perhaps less earlier estimations. In general, Machine Learning treatments are two types: unsupervised and supervised. Supervised strategies count on a specification priori of every feedback adaptable and map to technique outputs. Outputs end up parameters of interest example local climatic impacts. Unsupervised approaches are taking outputs of collected info, so the goal 
is identifying exciting patterns within the info and backlinks to inputs, just these are not used in advance. Novel human relationships are finding with the help of unsupervised learning, or perhaps tele-connections, water modelling across have different dimensions. A consequent fight on the global System team is going to be where an un-supervised reveals approach completely new program relation, wanting mechanistic recognition probabilistically.

Earth System Data
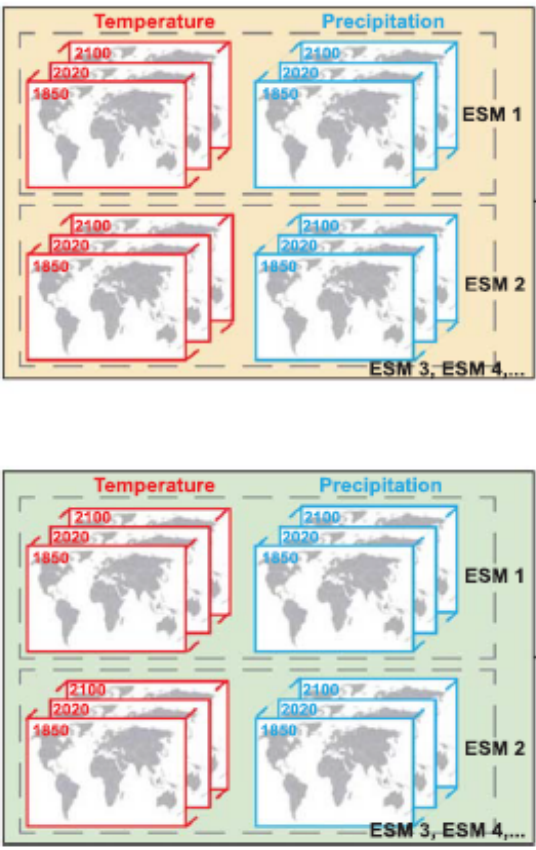

Different Al techniques

Examples

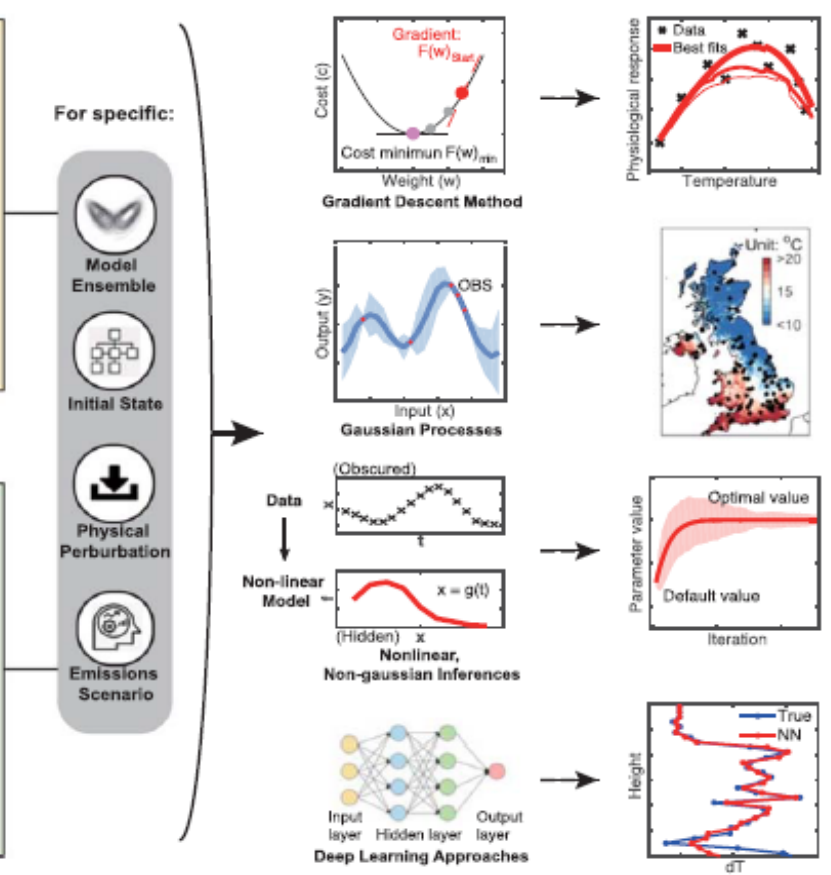

\section{$\mathrm{ML}$ and $\mathrm{Al}$-based understanding} enhances next generation ESMs

Figure 3. Methodology for applying different techniques of ML AND AI [45]

Deep-learning strategies latest pleasure around Machine Learning solutions centers on use of high networks as well as graphical architecture to uncover associations in nonlinear info. A directed graph is utilized by profound learning methods. Data are feedback at the starting, converted by secret amounts, and paper at top of the portion of the graph. An animating characteristic scales the conspicuous at each neuron, due to the weighted feedback from previous level. Instruction information set increase these weights and preference to furnished errors resilience. This specific learning later has helped mechanistic model construction.

AI to help climate adaptation, Recent Conference of Parties gatherings known as for constraining climate change to $2{ }^{\circ} \mathrm{C}$ above preindustrial quantities, or perhaps possibly even $1.5^{\circ} \mathrm{C}$. This process is huge. Directly after a brief plateau, development has been resumed by $\mathrm{CO} 2$ pollutants. Moreover, equilibrium climate change while for greenhouse gas concentrations might be or perhaps even extremely close $1.5^{\circ} \mathrm{C}$, and much more than farm land, warming is substantially 
greater. Nevertheless, income per capita is securely attached to energy usage, thus meeting social goals of a lot more people lead to different wealthier lifestyle will enhanced energy demand. Droughts are more impact climate events, thought to have \$ 1.5 billion cost internationally between the years 1998 to 2017, as well as represented $33 \%$ the cost of weather threats over that period. AI has the possibility wear latest advancements in drought forecasting accuracy to increase decision-making [45].

\section{Glacier retreat in the Himalayas}

The glaciated part of Indus basin is further divided into eighteen sub-basins namely Gilgit, Hanza, Indus, Astor, Shingo, Shigar, Drass, Suru, Nubra, Zaskar, PangongTso, Shyok, Chenab, Beas, Ravi, Sutlej, Spiti and Jhelum. The glaciated area is further differentiated as accumulation area comprising of $19265.98 \mathrm{sq} \mathrm{km}$ area and Ablation area comprising of $12961.53 \mathrm{sq} \mathrm{km}$ area. Depending upon the presence or absence of debris over glaciers, the Ablation area is even more divided as Ablation region ice exposed comprising $6310.58 \mathrm{sq} \mathrm{km}$ area and Ablation area debris covered comprising $6650.95 \mathrm{sq} \mathrm{km}$ area. The total area under permanent snowfields and glacieret is $991.68 \mathrm{sq} \mathrm{km}$ distributed in 5117 number of distinct occurrences in all the sub-basins. The highest number of occurrences of glacieret and snow fields is in the Indus subbasin which has 1080 number of such glacieret and snow field areas occupying about $108.7 \mathrm{sq} \mathrm{km}$ area. The Shigar sub-basin has 566 number of glacieret and snow fields and occupy a much larger area of $299.53 \mathrm{sq}$ $\mathrm{km}$. The inventoried Ganga basin has 6237glaciers occupying $18392.89 \mathrm{sq} \mathrm{km}$ of glaciated area. The total area under permanent snowfields and glacieret is 198.7 sqkm distributed in 641 numbers of distinct occurrences. The glaciated part of Ganga basin is further divided into 7 sub basins namely Yamuna, Karnali, Ghagara, Alaknanda, Bhagirathi, Kosi and Narayani as per the location of theirs from west to east. While the Karnali sub-basin is the larglargest sub-basin, the Bhagirathi sub-basin is the smallest in the Ganga Basin. The glaciers in the Ganga basin are located from decreased elevation of approx. $2564 \mathrm{~m}$ a.s.l. in Ghagra basin to as high as approx. $6312 \mathrm{~m}$ a.s.l. in Kosi sub-basin. The total range under permanent snowfields and glacieret is $198.7 \mathrm{sq} \mathrm{km}$ distributed in 641 numbers of distinct occurrences in all the sub-basins. The highest number of occurrences of glacieret and snow fields (GS) is in the Alaknanda sub-basin which has 186 numbers of glacieret and snow fields occupying $24.51 \mathrm{sq} \mathrm{km}$ area. All the sub-basins of Ganga basin show the presence of GS. The Ghagra sub-basin has 113 number of glacieret and snow fields occupying a much larger area of $44.35 \mathrm{sq} \mathrm{km}$. In Brahmaputra valley, approximately $1282.92 \mathrm{sq} \mathrm{km}$ area was covered with permanent snow having 3651 number of distinctoccurrences[18].

Table 2. Glacier Retreat Rates for Selected Glaciers

\begin{tabular}{|l|l|l|l|}
\hline Glacier & $\begin{array}{l}\text { Observation } \\
\text { Period }\end{array}$ & $\begin{array}{l}\text { Average retreat } \\
\text { or advance rate } \\
(\mathrm{m} / \mathrm{yr})\end{array}$ & Reference \\
\hline Gangotri & $1935-1971$ & -26.50 & Bali et al., 2011 \\
& $1962-1999$ & -33.8 & Naithani, 2001 \\
& $1971-2004$ & -17.50 & Bali et al., 2011 \\
& $2004-2005$ & -12.10 & Kumar et al., 2008 \\
& $2006-2010$ & Stable & Kargel et al., 2008 \\
\hline
\end{tabular}


Rahul Malik et al.

\begin{tabular}{|c|c|c|c|}
\hline & $\begin{array}{l}1935-2004 \\
1965-2006 \\
2004-2007 \\
1934-2003 \\
1842-1935 \\
2007-2009\end{array}$ & $\begin{array}{l}-22.0 \\
-20.0 \\
-11.9 \\
-12.0 \\
-7.3 \\
\text { Stable }\end{array}$ & $\begin{array}{l}\text { Kumar, } 2008 \\
\text { Bhambri, 2012 } \\
\text { Sangewar\&Kulkarni,2007 } \\
\text { Bagla, 2009 } \\
\text { Hasnain, } 2002 \\
\text { Raina, 2009 }\end{array}$ \\
\hline Pindari & $\begin{array}{l}1845-1906 \\
1906-1958 \\
1958-1966 \\
1966-2007 \\
\end{array}$ & $\begin{array}{l}-26.23 \\
-20.0 \\
-7.62 \\
-6.39 \\
\end{array}$ & $\begin{array}{l}\text { Bali et al., } 2011 \\
\text { Bali et al., } 2011 \\
\text { Bali et al., } 2011 \\
\text { Bali et al., } 2011 \\
\end{array}$ \\
\hline Tipra & $1962-2008$ & -14.41 & Mehta et al., 2011 \\
\hline Dokriani & $\begin{array}{l}1962-1995 \\
1993-1998 \\
1962-2007 \\
1991-1995 \\
\end{array}$ & $\begin{array}{l}-16.67 \\
-16.5 \\
-17.0 \\
-17.4 \\
\end{array}$ & $\begin{array}{l}\text { Dobhal et al., } 2004 \\
\text { Down to Earth, } 1999 \\
\text { Sangewar\&Kulkarni,2007 } \\
\text { TNN, } 2007\end{array}$ \\
\hline Kangriz & $1910-2007$ & Stable & Raina, 2009 \\
\hline Siachin & $\begin{array}{l}1862-1909 \\
1909-1929 \\
1929-1985 \\
1985-2004 \\
2004-2005 \\
1991-2000 \\
2000-2007 \\
\end{array}$ & $\begin{array}{l}-15.42 \\
-14 \\
\text { Stable } \\
-3 \\
\text { Stable } \\
-17.8 \\
-15.7 \\
\end{array}$ & $\begin{array}{l}\text { Ganjoo, } 2010 \\
\text { Ganjoo, } 2010 \\
\text { Ganjoo, } 2010 \\
\text { Ganjoo, } 2010 \\
\text { Ganjoo, } 2010 \\
\text { Ganjoo, } 2010 \\
\text { Ganjoo, } 2010 \\
\end{array}$ \\
\hline Miyar & 1961-1996 & -16.0 & Kulkarni, 2011 \\
\hline DrangDrung & $1975-2008$ & -3.96 & Kamp, 2011 \\
\hline Zanskar & $1975-2006$ & -27.1 & Kamp, 2011 \\
\hline SamudraTapu & $1962-2000$ & -20.0 & Kulkarni, 2006 \\
\hline Hamtah & 1961-2005 & -8.0 & Kulkarni, 2011 \\
\hline ChhotaShigri & $\begin{array}{l}1962-1995 \\
2003-2006 \\
\end{array}$ & $\begin{array}{l}-13.44 \\
-0.98 \\
\end{array}$ & $\begin{array}{l}\text { Kulkarni, } 2011 \\
\text { Wagnonetal, } 2007\end{array}$ \\
\hline Bara Shigri & $\begin{array}{l}1906-1995 \\
1890-1906 \\
1977-1995 \\
\end{array}$ & $\begin{array}{l}-30.0 \\
-20.0 \\
-36.1 \\
\end{array}$ & $\begin{array}{l}\text { Kulkarni, } 2011 \\
\text { Mayekwski, } 1999 \\
\text { Cruz et al., } 2007 \\
\end{array}$ \\
\hline Satopanth & $\begin{array}{l}1962-2006 \\
2005-2006 \\
\end{array}$ & $\begin{array}{l}-22.0 \\
-6.5 \\
\end{array}$ & $\begin{array}{l}\text { Nainwal, } 2008 \\
\text { Nainwal, } 2008 \\
\end{array}$ \\
\hline $\begin{array}{l}\text { Bhagirathi } \\
\text { Kharak }\end{array}$ & $\begin{array}{l}1962-2001 \\
1962-2006 \\
\end{array}$ & $\begin{array}{l}-16.7 \\
-7.3 \\
\end{array}$ & $\begin{array}{l}\text { Sangewar, } 2011 \\
\text { Nainwal, } 2008\end{array}$ \\
\hline Milam & $\begin{array}{l}1948-1997 \\
1849-1957 \\
1909-1984 \\
\end{array}$ & $\begin{array}{l}-17.0 \\
-12.5 \\
-13.2 \\
\end{array}$ & $\begin{array}{l}\text { Sangwar, } 2011 \\
\text { Vohra, } 1981 \\
\text { Cruz et al., } 2007\end{array}$ \\
\hline Burphu & 1966-1997 & -5.0 & Kulkarni, 2011 \\
\hline Jhulang & $1962-2000$ & -5.6 & Oberoi, 2001 \\
\hline Meola & $1912-2000$ & -18.4 & Sangwar, 2011 \\
\hline Chipa & $1961-2000$ & -27.0 & Oberoi, 2001 \\
\hline Zemu & $\begin{array}{l}1976-2005 \\
1977-1984 \\
\end{array}$ & $\begin{array}{l}-14.10 \\
-27.7 \\
\end{array}$ & $\begin{array}{l}\text { Raina, MoEF } \\
\text { Cruz et al., } 2007\end{array}$ \\
\hline Poting & 1906-1957 & -5.0 & Vohra, 2005 \\
\hline Dunagiri & $1992-1997$ & -4.84 & Swaroop et al, 2006 \\
\hline Chorabari & 1992-1997 & -11 & Swaroop et al., 2006 \\
\hline
\end{tabular}


Rahul Malik et al.

\begin{tabular}{|l|l|l|l|}
\hline Moru & $1997-2000$ & -17.17 & Chitranshi et al, 2007 \\
\hline Beas kund & $1980-2006$ & Shrunk to half & TNN, 2007 \\
\hline CKatru & $1980-2006$ & -54.0 & TNN, 2007 \\
\hline Batal & $1980-2006$ & -25.7 & TNN, 2007 \\
\hline $\begin{array}{l}\text { K日rhani } \\
\text { e }\end{array}$ & $1857-1909$ & -15.0 & Mayekwshi, 1979 \\
\hline Naradu & $1912-2008$ & -16.0 & Kulkarni, 2011 \\
\hline Trsta & $2001-2003$ & -0.4 & Koul\&Ganjoo, 2009 \\
\hline Shankalpa & $1976-2005$ & -14.83 & Raina, 2009 \\
\hline Rătanban & $1886-1957$ & -7.0 & Kulkarni, 2011 \\
\hline Trlloknath & $1962-2002$ & -13.26 & Mehta et al., 2011 \\
\hline
\end{tabular}

The sub-basins of GiamdaChhu, Lohit and Dihang/Siang are covering 430, 195 and $160 \mathrm{sq} \mathrm{km}$ respectively. However, Kameng and Gangadhara have shown the highest mean distribution of 5.76 and 1.55 respectively in Brahmaputra basin.

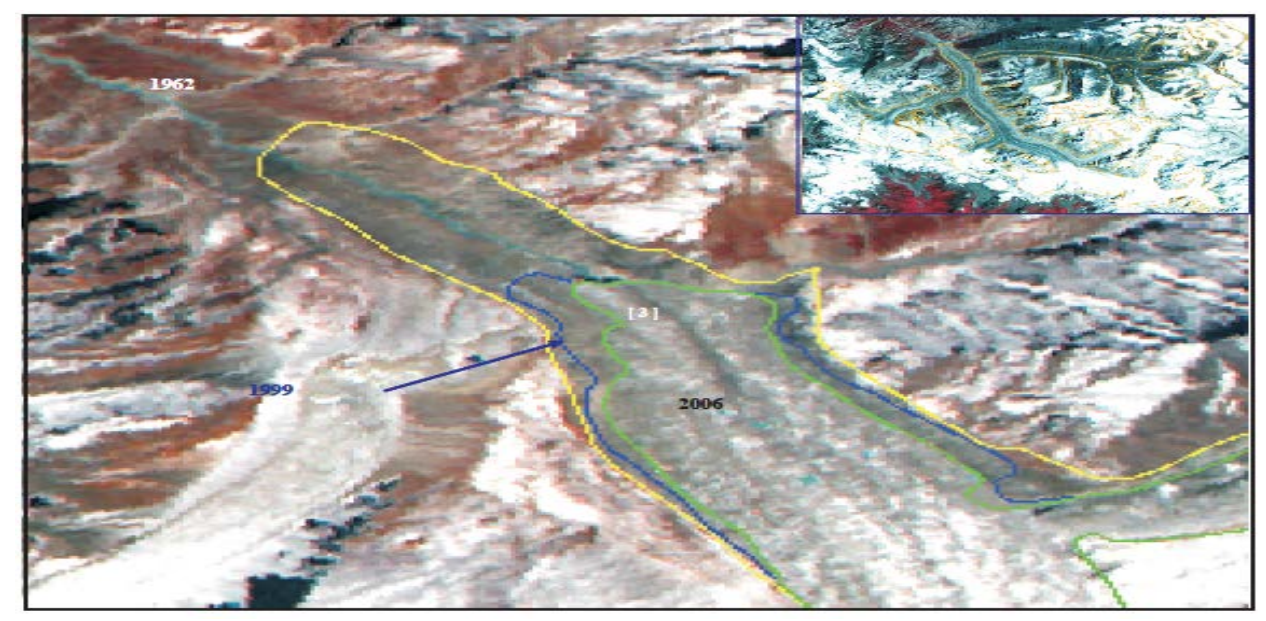

Figure 4. IRS LISS III Image showing full view of Gangotri glacier(left) and retreat of its snout from 1962 to 2018

In the Himalayan region, glaciers as well as ice cover were thinning after the conclusion of 20th century consistent with the worldwide fashion. With substantial snout fluctuations, virtually all the Himalayan glaciers retreating at rates that are accelerated within the previous three decades [19] plus the rate of theirs of retreat is a lot quicker than that of glaciers in other areas of the world. These changes fit to the soaring floor high heat trends in the Himalayas which are found being bigger compared to the worldwide average warming.

World Glacial Monitoring Service (WGMS) ice and Snow maintains collection of mass harmony of glaciers. This particular company is publishing data for glacier mass balance after 1967 in the amount of Fluctuations of Glaciers after each five years. Review of almost 10 to 15 glaciers after 1991 was printed in Glacier Mass Bulletin. Dyurgerov(2002) and Meier and Dyurgerov (2005) has been doing comprehensive evaluation of worldwide mass harmony of the glacier information for period 1946 to 1998. They deduced that in between 1961 to 1998, the typical mass balance identified worldwide is $212 \mathrm{~mm}$ w.e.units, showing $93 \mathrm{~mm}$ for -294 
and 1961-1976 mm for 1977 1998. Numerous scientific studies are performed on the fluctuation of glaciers in the Indian Himalaya along with changes that are significant (mostly retreats) are captured within the last 3 years. Research claim that nearly all glaciers are retreating also the speed of retreat differs from a number of meters to as large as sixty one $\mathrm{m} / \mathrm{year}$. The getaway of selected glaciers is summarized in Table two; many of these glaciers are retreating discontinuously since the post glacial period (Table 2).

For instance, the Siachen Glaciers retreated at a speed of $31.5 \mathrm{~m}$ per season respectively [20]. On the foundation of earlier observations between the 1991 to 2000 together with 2000 to 2007 the glacier has reduced approximately $161.5 \mathrm{~m}$ and $110 \mathrm{~m}$ with an average cost of $17.8 \mathrm{~m} /$ year in addition to $15.7 \mathrm{~m} /$ year respectively. Mizraet al., (2002) thought the getaway of $20 \mathrm{~m}$ in season 1998 as well as as opposed an annual average of $16.5 \mathrm{~m}$ more than 19931998 at Dokriani glacier. Gangotri glacier is diminishing at the pace of around 26m/year between 1935 also as $1971,17 \mathrm{~m} /$ year simple fall in between 1971 also as 2004 , and also in the latest past indicates a recession number of aproximatelly 12m/year during 2004200542. The deglaciation of $6 \%$ in common feature of Gangotri glacier was seen by Negi et al. (2012) between the years 1962 to 2006. The acceleration of downturn on the Pindari glacier has appeared right down to $6.5 \mathrm{~m} /$ year in comparison to the sooner found acceleration of 26m/year between 1996 and 2007 also the Milam glacier is found as $16.5 \mathrm{~m} /$ year within the past 150 years [21].

In an investigation, Nainwal et al. (2008) discovered the snout of the Donagiri glacier has proven symptoms of moderate downturn, therefore the Satopanth glacier which is diminishing at the acceleration of $22.86 \mathrm{~m}$ /year earlier, has lately proven a downturn quantity of $6.5 \mathrm{~m}$ /year during 2005, 2006. Glacier Mass balance for Chhotashigri and bara Shigri are $1.31 \mathrm{~m} / \mathrm{a}$ w.e. (water equivalent) plus $1.12 \mathrm{~m} / \mathrm{a}$ w.e. respectively. Mass balance estimation in 20002001 plus 2001 to 2002 in the Baspa area (H.P) are $0.9 \mathrm{~m} / \mathrm{a}-0.78 \mathrm{~m} / \mathrm{a}$ and w.e. w.e. 44 that has the AAR technique using Remotesensing information. Between the years 2005 to 07, the Gangotri glacier has retreated at much reduced rates $(11.80 \pm 0.035 \mathrm{ma} 1)$, BhagirathiKharak glacier had retreated 319.34 with a normal cost of $7.42 \mathrm{~m} /$ year from 1962 to 2005, DurungDrung icy mass escape at a normal cost of $3.96 \mathrm{~m} / \mathrm{yr}$ though advance is caught in the east at a normal cost of $0.65 \mathrm{~m} /$ year. The typical price of getaway of glaciers in Sikkim has been estimated to be aproximatelly $13.02 \mathrm{~m}$ per season from1976 to 2005. Out of a full twenty six glaciers that have been analyzed, twelve glaciers had retreated at a quicker rate than the common $(13.02 \mathrm{~m}$ per year). The mean damage of glacial measurements for 4 years is approximately $621 \pm 468 \mathrm{~m}$. This implies that ice sheets in various districts of the Himalaya react in an unexpected way[22].

Retreat of individual ice sheets might be impacted by neighborhood geomorphic and climatic factors and probably won't speak to nearby alterations in climatic issue. Along these lines, it will be essential to assess long haul all out changes in frosty level. Of late, logical examinations had been performed to see general changes in frosty degree in different areas of the Himalaya. Practically [23]30 \% general harm in ice sheet area inside the most recent forty years, in light of a few landscape and furthermore geomorphological parameters (Table three) is proposed by the logical examinations. Numerous logical investigations led in the Himalayan zone have explained the impact of warmth as a huge controlling element for frosty change. Snow spread checking as a result of the period 1997 to 2001 is performed in the Beas basin. Bhambri et al. (2011) used Aster and Corona pictures of 1968 just as 
2006 to outline ice sheets in the Saraswati/Alaknanda and Bhagirathi bowls on the Garhwal Himalaya.

The investigation uncovered that the icy mass cleared something of aproximatelly $4.62 .8 \%$ with the downturn expenses developing all the more of late (1990 to 2006). The bowl exhibited to fracture that brought about an ascent in the measure of icy masses from eighty two (1968) to eighty eight (2006). Some land mark logical investigations utilizing remote detecting data are now perpetrated on gauge the ice sheet escape for 466 ice sheets in Chenab, Baspa and Parbati basins [24] indicating a general deglaciation of twenty one \% during 1962 to 2001. Few spearheading logical investigations on the escape of Parbati Glacier50 and escape of ice sheets in Parbati sub basin were completed. By the by, the examination represents only eighty eight ice sheets outside of 153 ice sheets mapped by GSI in the Parbati sub bowl. The present examination is considerably more broad as change identification of 169 ice sheets of the Parbati bowl for some is incorporated by it approximately three decades[25].

Kulkarni et al (2011) have endeavoured to perceive the alterations in the Himalayan Cryosphere applying remote detecting techniques. From the investigations of theirs on the changes in cold level, frigid mass parity just as regular snow spread; they've accepted the icy escape for 1868 ice sheets in eleven bowls after 1962 at sixteen \% (by and large deglaciation). The checking of the regular ice inclusion in twenty eight stream sub bowls in western and focal Himalayas, according to them, demonstrated snow retreat while during winters. The sub basin sensible glacier inventory summary statistics offers a way to evaluate the glacier features among the glaciated sub basins [44]. Evaluation of inventory information is carried through to recognize the wide distribution of glaciers across numerous sub basins. Critically analysed glacier inventory information are able to present an insight on the behaviour along with the all-around health of glaciers and the glaciated basins. For this particular every one of the glacier features is analysed independently and along with some other related glacier features.

Table 3. Loss/gain in area $\left(\mathrm{km}_{2}\right)$ of glaciers in several basins primarily based on Survey of India (SOI) maps and satellite pictures.

\begin{tabular}{|c|c|c|c|c|c|c|}
\hline S.No. & Sub-Basin & $\begin{array}{l}\text { No.ofglacier } \\
\text { monitored }\end{array}$ & $\begin{array}{l}1962 / 1969 * \\
(\mathrm{Km} 2)\end{array}$ & $\begin{array}{l}2001 / 2004 * \\
\text { /2005\# }\end{array}$ & $2018 / 2019$ & $\begin{array}{l}\text { Loss in } \\
\text { area \% }\end{array}$ \\
\hline 1. & Chandra & 116 & 696 & 554 & 521 & 20 \\
\hline 2 & Bhaga & 111 & 363 & 254 & 232 & 30 \\
\hline 3. & Warwan & 230 & 740 & 608 & 581 & 18 \\
\hline 4. & Bhut & 143 & 450 & 417 & 402 & 7 \\
\hline 5. & Miyar & 165 & 568 & 523 & 504 & 08 \\
\hline 6. & Alaknanda & 274 & 1047 & $905 \#$ & 882 & 14 \\
\hline 7. & Bhagirathi & 183 & 1218 & $1074 \#$ & 1024 & 11 \\
\hline 8. & Dhauliganga & 104 & 429 & $362 \#$ & 343 & 16 \\
\hline 9. & Suru & 215 & $568^{*}$ & $474 *$ & 442 & 17 \\
\hline 10. & Zanskar & 631 & 1107 & 940 & 911 & 15 \\
\hline 11. & Parbati & 90 & 493 & 390 & 342 & 20 \\
\hline 12. & Spiti & 337 & 474 & 396 & 331 & 16 \\
\hline 13. & Nubra & 31 & $2150^{*}$ & 2026 & 1982 & 6 \\
\hline 14. & Chenab & 358 & 1414 & 1110 & 1092 & 21 \\
\hline 15. & Baspa & 19 & 173 & 140 & 115 & 19 \\
\hline
\end{tabular}


Rahul Malik et al.

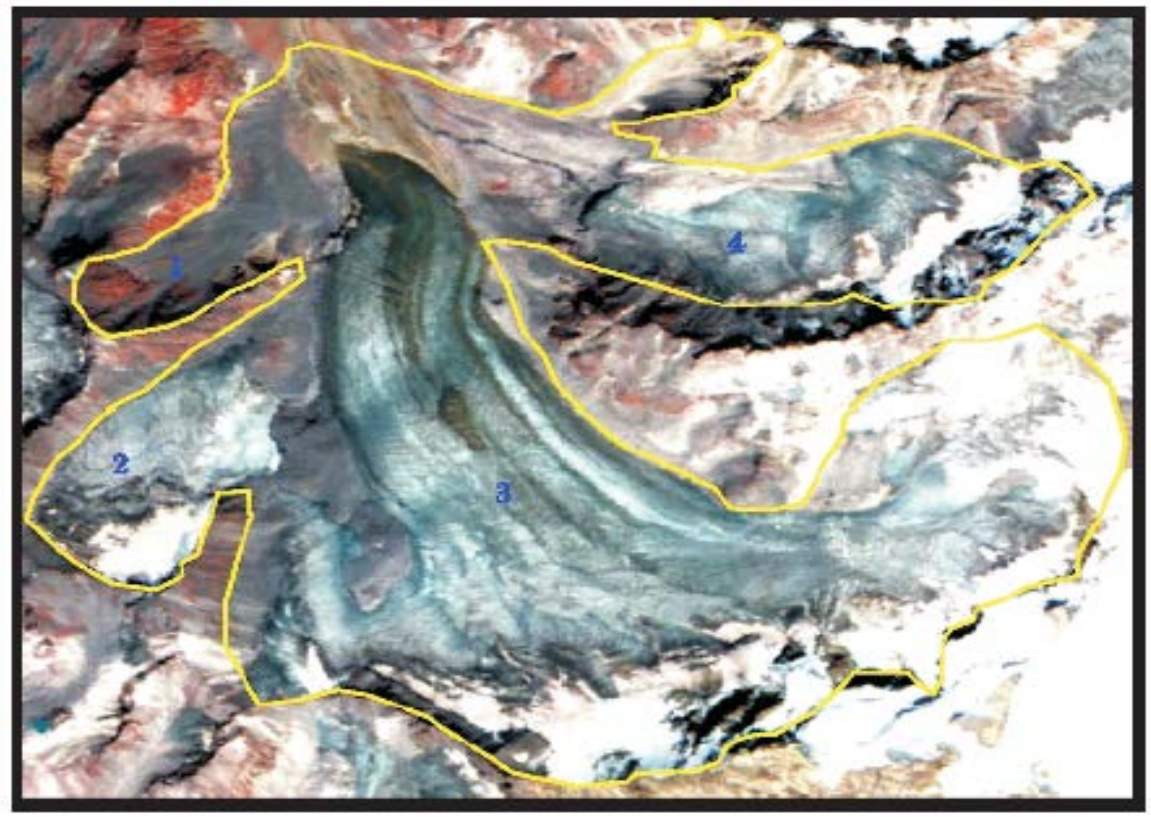

Figure 5. Retreat and fragmentation shown on IRS LISS IV image covering glaciers of Parbati basin. The boundary of glacier is taken from SOI map of 1962 [11].

The analysis supplied a' wide request of-extent' assessment of the frosty mass equalization towards the last part of the 21st century. The most recent i.e., season 2000 frosty mass mischief was thought as $-6.6 \pm 1 \mathrm{Gt}$ yr. The mass mischief is anticipated to lift to $-12 \pm 1$ and furthermore $-14.4 \pm 1 \mathrm{Gt}$ yr one in 2030 s, just as $12 \pm 2$ and $-35.5 \pm 2$ Gt yr one in 2080s, under the RCP 2.6 and RCP 8.5 condition, separately. The investigation unquestionably infers that a quick alleviation of Green House Gas outflows for example a move from the RCP 8.5 pathway to RCP 2.6 might stop over sixteen \% of the glaciated location from' eventual disappearance' towards the tail end of the century[26].

\subsection{Glacier Lakes}

Ice sheet development notwithstanding collaboration with particles inclusion on ice sheet surfaces prompts different ice sheet surface highlights. With significant expenses of softening, these surface highlights style ice sheet lakes. The development or vanishing of progressive supra-glacial lakes is a characteristic event. Albeit an expansion aggregate and territory of supra-glacial lakes on the icy mass top part may be associated with significant expenses of ice liquefying and maybe in abundance of down wasting of the ice sheets. The blending of the little lakes brings about huge ice sheet lakes which will keep gigantic measures of water and residue.

The cold moraine limit joins delicate and free materials. Soak parallel moraines with incredibly insecure slopes lie against the lofty ice sheet tongues. Indeed, even minimal seismic movement, an avalanche, ice calving, or day off rock torrential slides are skilled to bring about the startling arrival of a tremendous measure of drinking water, which lead to streak floods downstream. These icy mass lake upheaval crowds (GLOFs) can prompt critical issues for occupants and furthermore 
the framework of theirs, just as to the biological system and world on Himalayan locale. Numerous ice sheet lakes have made in the earlier 50 years in the Himalaya, likely obvious proof environmental change. On the off chance that the current icy mass down wasting course stays, substantially more possibly perilous moraine dammed lakes are probably going to assemble. Subsequently, it is critical to build up the plausible GLOF locales in the Himalaya in this way required preventive techniques may be used[27].

Furthermore, a number of glacier lake scientific tests are done within the Indian together with the Himalaya. The outcomes displayed GLOF potential destinations inside the Dhauligganga. The territory of best chilly lake in 1989 was approximately $0.15 \mathrm{~m} 2$; the elements of another little ice sheet lakes ran from 0.025 to $0.075 \mathrm{~km} 2$. As of late, a beginner driver evaluation of two ice sheet lakes inside the Ganga area was led by using Landsat 1978, Landsat 1990, also Landsat 2001 pictures. The outcomes indicated that, after 1978, the huge icy mass lake region in Ganga headwaters continues to grow by approximately forty \%, even though the component of the reduced sized lakes continues to grow by just approximately $13 \%$. The study indicates that every hydrodynamics as well as calving are large jobs that restrict the glacier lake expansion [28].

The Geological Society of India (2008) included the' Glacier Atlas of India' to supply an exact and current measurement program portrayal of the present icy mass inclusion for the Indian together with the Himalayas [29]. Icy mass methodology and landforms, which incorporates cold lakes, are expressed in the post, albeit no efficient mapping of frigid lakes was performed. The results are likely risky: Tibet 441 lakes, seventy seven insidious; Nepal 2315 lakes, twenty insidious; Bhutan 2674 lakes, twenty six dangerous; and India 356 lakes, twenty two dangerous.

Table 4. Summary of glacier, glacier lakes and potentially dangerous glacial lakes in India during 1999-2018

\begin{tabular}{|c|c|c|c|c|c|c|}
\hline \multirow{2}{*}{$\begin{array}{l}\text { River } \\
\text { Basins }\end{array}$} & \multicolumn{3}{|l|}{ Glaciers } & \multicolumn{3}{|c|}{ Glacier Lakes } \\
\hline & Number & $\begin{array}{l}\text { Area } \\
\left(\mathrm{Km}^{2}\right)\end{array}$ & $\begin{array}{l}\text { Ice Reserve } \\
\left(\mathrm{Km}^{2}\right)\end{array}$ & Number & $\begin{array}{l}\text { Area } \\
\left(\mathrm{Km}^{2}\right)\end{array}$ & $\begin{array}{l}\text { Potential } \\
\text { danger }\end{array}$ \\
\hline Beas & 358 & 758 & 76.40 & 59 & 236.20 & 5 \\
\hline Ravi & 198 & 235 & 16.88 & 17 & 9.16 & 1 \\
\hline Chenab & 681 & 1705 & 187.66 & 33 & 3.22 & 5 \\
\hline Satluj & 945 & 1218 & 94.45 & 40 & 136.46 & 3 \\
\hline $\begin{array}{l}\text { Himachal } \\
\text { sub-basins }\end{array}$ & 372 & 245 & 11.96 & 7 & 0.18 & 2 \\
\hline Yamuna & 124 & 173 & 17.88 & 20 & 0.17 & 0 \\
\hline Bhagirathi & 393 & 1034 & 143.41 & 32 & 0.44 & 0 \\
\hline Alaknanda & 540 & 1675 & 191.36 & 54 & 1.37 & 0 \\
\hline Kali & 382 & 1178 & 122.78 & 21 & 0.51 & 0 \\
\hline Total & 3993 & 8221 & 862.78 & 283 & 387.71 & 16 \\
\hline
\end{tabular}

\subsection{Sea Level Rise}

The most recent numerous years, ocean level ascent made by the effects and environmental difference in its on shoreline zones has spun into an issue of developing interest with the therapeutic culture, furthermore to overall population and the press. It is presently more made that the Earth's atmosphere is warming that the primary driver will be the development of regular house gases (GHGs) in the 
planet, created by anthropogenic non-renewable energy source burning just as change in land use (generally deforestation) [30]. Environmental change has offered ascend to a ton of unmistakable impacts, especially advancement of the Earth's forceful region temperature and of marine warming content, dissolving of marine ice and glaciers and damage of ice mass from the Greenland and Antarctica ice sheets [31]. Sea warming prompts winter improvement of marine waters, thus ocean level ascent. Moreover, water from land ice dissolve inevitably jumps on the seas, subsequently also comes about ocean level ascent. Perceptions furthermore show which the quickening of rise shows phenomenal territorial variations. Displaying of conceivable environmental change under various radiative driving situations shows that ocean level proceeds to help during the ensuing years notwithstanding centuries.

Harming outcomes of ocean level increment in seaside regions are commonly considered as a significant danger to environmental change in the event that see that $10 \%$ of the world overall population is dwelling in beach front zones rather under $10 \mathrm{~m}$ above marine level. Twentieth century perceptions content shoreline disintegration in a ton of regions over the world coastlines however it's as yet uncertain whether this is because of climate related ocean level rise or maybe too much increasingly nearby non climatic things like soil subsidence (causing far off relative ocean level ascent), shoreline overseeing, shortfall in silt supply, and so forth., and perhaps on the mix of all factors [32]. In any case, it is basically sure that in the succeeding yrs, the foreseen speed of ocean level expanded reaction to persistent environmental change will disturb the weakness of innumerable low lying, profoundly populated waterfront areas of the world, and presumably get yourself a significant risk a couple of years not far off for a huge piece of individuals.

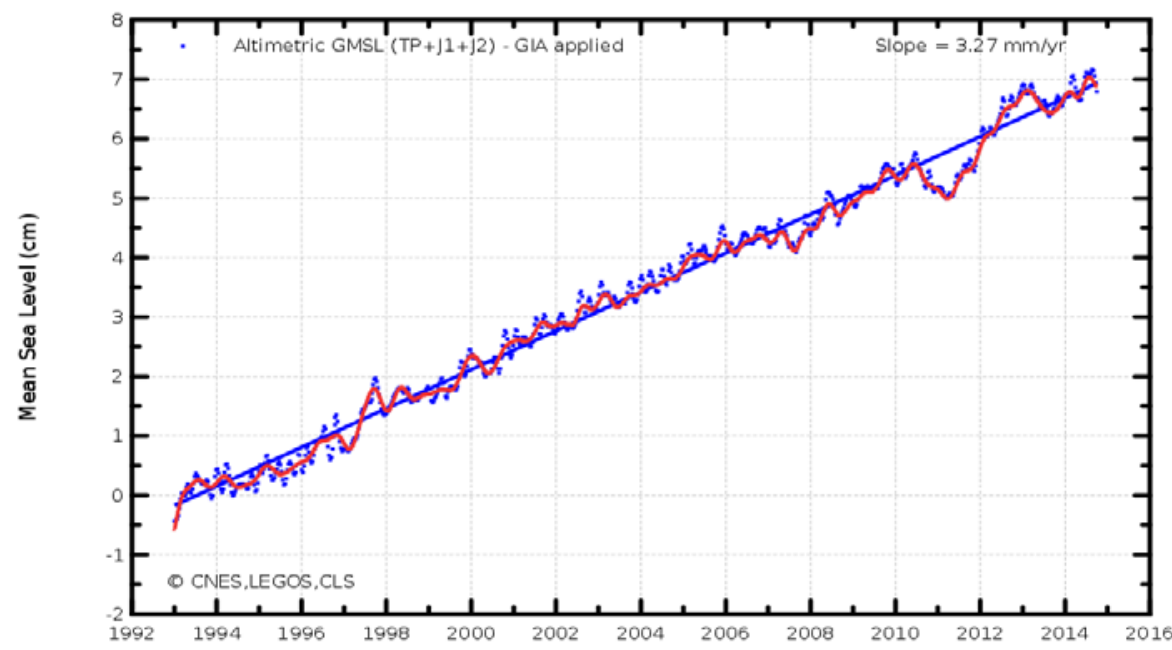

Figure 6. Global mean sea level sequence and associated uncertainty dependent on tide gauge data more than twentieth century(satellite alimentary details over 1993 2019; average information from various groups) [28].

Usually, over the satellite sensing period (1993 to 2019), the commitment top maritime heat to all-inclusive mean ocean level ascent profiles. From amount and furthermore mass equalization investigations of a lot of ice sheets grounded upon 
different in situ and remote detecting perception systems, gauges are made of the commitment of icy mass liquefy to ocean level rise. For the period 1993 to 2009/2012, ice sheets alongside ice tops having represented $30 \%$ worldwide unfriendly ocean level rise (IPCC (2007a) gives $18-59 \mathrm{~cm}$ rise as the projection at 2100). [33].On moderate the ice commitment to ocean level ascent over the alarming time adds up to generally 20S. The zone based perceptions unambiguously exhibit pace of ice sheet mass damage inside the freshest year. In spite of the fact that their commitment keeps on becoming after2000 to 2003, for the period 1993 to 2003, fairly under $15 \%$ of the increasing speed of worldwide ocean level ascent was as a result of the ice sheets.

There is almost no issue that sea level will still surge in the later years as well as centuries [34]. The majority of present projections of the up and coming ocean level ascent from outfit methods for process climate models guarantee that by 2100 , worldwide mean ocean level must be generally more rather than right now in the collection of forty seventy five $\mathrm{cm}$, in view of the radiative constraining scenario. Representing model scattering prompts an even bigger choice from 25 to ninety five $\mathrm{cm}$. Medium warming situations compute a global mean marine level rise of $\sim 50 \mathrm{~cm}$ by 2100 while an evaluation of $\sim 75 \mathrm{~cm}$ is anticipated for the more warming condition. Sea warming, ice sheets liquefying, and furthermore ice mass damage will bring $45 \%, 206 \%$, and $203 \%$, separately, the remaining because of land water extra room move. These extents are fundamentally absolutely equivalent to some situations.

\section{Climate Change Observation}

Warming on the weather framework is unequivocal, and since the 1950s, a lot of the saw improvements are extraordinary over decades to centuries. The air and sea have warmed, the quantity of ice and ice have diminished, and ocean level has risen

The process that have been increasing since 1976 and threatening the world is the global warming. The important consequences that have been observed during recent decade are the thinning and shrinking of mountain type glaciers. The possible causes for global warming are anthropogenic activities like escalation in the combination of aerosols and green gases, along with alteration in land use cover as per IPCC report. The previous done observations suggested that temperature increases with the increase in elevation which makes plateau and mountain range susceptible to global warming[35]. India shows an increasing trend of mean annual temperature from 1903-2003 of around 0.50C/100yrs. And from 1970 onwards the increase in temperature found to be $0.210 \mathrm{C} / 10$ years. This happens because northern part of country experience significant warming during that period and surge of temperature rise since nineties. Indian subcontinent also have noted many changes in the distribution pattern of temperature and precipitation over last fifty years revealing that there is a change in frequency of different types of rain events from 1954-2004, which in turn showing that summer monsoon over India is weak. The meteorology data obtained during last thirty year over these glacierized region i.e. high altitude regions also showed that there is increase in global warming and abatement in the snowfall in various extents of North-western Himalayas, showing temperature rise of around 1.60C during 1901-2000 [36].

According to the IPCC Fifth Assessments reports Worldwide Surface Temperature has ascended after the end nineteenth century. The entirety of the late three years is progressively more smoking at the Planet's surface region than all the 
earlier years in the key record, just as certainly the underlying 10 years of the 21st century will keep on being potentially the hottest. The internationally arrived at the midpoint of consolidated land alongside marine region temperature information as determined by a straight example, plainly exhibit a warming of $0.85 \mathrm{C}$, period 1880 to 2012, when a couple autonomously made datasets exist, and approximately $0.72 \mathrm{C}$ [0.49C to $0.89 \mathrm{C}$ ] over the period 1951 to 2012 . The entire improvement between the 2003 to 2012 timeframe is $0.78 \mathrm{C}$, in view of the largest dataset accessible. The most likely the lengthiest duration when computation of neighborhood design is satisfactorily broad, for all intents and purposes entire world has experienced floor warming. Alongside solid multi decadal warming, significant decadal and interannual fluctuation is displayed by worldwide mean surface warmth. Inferable from natural inconstancy, style dependent on brief records are staggeringly vulnerable to the novice and end dates and don't as a rule reflect long haul climate patterns.

No matter, all worldwide joined LSAT and SST information show a factually non-significant heat pattern definitely more than 1998 to 2012 (0.042C 0.093C per 10 yrs. (HadCRUT4); $0.037 \mathrm{C}$ to $0.085 \mathrm{C}$ per ten years (NCDC MLOST); 0.069C to 0.082C every decade (GISS)). A normal of the crazes for three information creates an expected changed for the 1998 to 2012 time of 0.05 C per 10 years. Patterns extremely brief length are helpless to right time frame decision with dress evaluated in style that is comparative of the multi-year times beginning in 1995, 1996, just as 1997 directly being 0.13 [0.02 to 0.24 ], 0.14 [0.03 to 0.24 ] likewise as 0.07 [0.02 to 0.18 ] (all C every decade), separately [37].

\subsection{Strong Evidence of Warming}

Atmosphere information in the Himalayas shows a warming example, yet at costs which will move in times which will change according to the spots and besides months (Table 5). In a late regional research with Climate Research Unit's changed atmosphere dataset, Diodato et al. (2011) show that inside the latest couple of years the Himalayan and Tibetan Plateau zone have heat at a speed over that inside the twentieth century. They obviously display a $0.5^{\circ} \mathrm{C}$ in yearly normal perfect warmth (Tmax) warming more than 1971to 2005 when appeared differently in relation to 1901 to 1960.

Table 5. Outline of temperature Trend Studies in the Himalayas (NS= Number of Stations; DT=Tremperature information type (RG=reanalysed matrix; $S=$ =station; $\mathrm{M}=$ monthly);SS=Statistical centrality)

\begin{tabular}{|l|l|l|l|l|l|}
\hline Region & NS & DT & Trend(*C/Decade) & $\begin{array}{l}\text { Analysis } \\
\text { Period }\end{array}$ & SS \\
\hline $\begin{array}{l}\text { Western } \\
\text { Indian } \\
\text { Himalaya }\end{array}$ & & RG(M) & Tmax: 0.11 & $1901-2017$ & NA \\
\hline & 10 & $\mathrm{~S}(\mathrm{M})$ & $\begin{array}{l}\text { Tav, Northwest: 0.12(A*),0.15 } \\
\left(\mathrm{W}^{* *}\right)\end{array}$ & $1876-2016$ & $5 \%$ \\
& 8 & $\mathrm{~S}(\mathrm{M})$ & $\begin{array}{l}\text { Tav;0.25-0.45(w); Tmax:0.07 to } \\
0.17(w) \text { Tmin:0.336 to 0.833(w) }\end{array}$ & $1975-2017$ & $\leq 5$ \\
\hline & 4 & $\mathrm{~S}(\mathrm{M})$ & Tav, Northwest:0.17(A),0.18(W) & $1901-2018$ & $5 \%$ \\
\hline & 1 & $\mathrm{~S}(\mathrm{M})$ & $\begin{array}{l}\text { Tmax, Lower Indus: All seasons and } \\
\text { year (0.53 to 0.113; 0.139 Annual) }\end{array}$ & $\begin{array}{l}20^{\text {th }} \text { century } \\
(90-100 \text { years) }\end{array}$ & $5 \%$ \\
\hline Eastern & & RG(M) & Tmax:0.2(A) & $1901-2017$ & NA \\
\hline
\end{tabular}


Rahul Malik et al.

\begin{tabular}{|l|l|l|l|l|l|}
\hline $\begin{array}{l}\text { Indian } \\
\text { Himalaya }\end{array}$ & & & & & \\
\hline & 8 & $\mathrm{~S}(\mathrm{M})$ & $\begin{array}{l}\text { Tav: }-0.2 \text { to } 0.8 ; \text { Tmax:0.1to0.9; } \\
\text { Tmin: }-0.5 \text { to } 0.8\end{array}$ & $\begin{array}{l}1960 \mathrm{~s} / 70 \mathrm{~s}-201 \\
8\end{array}$ & $5 \%$ \\
\hline
\end{tabular}

*A=Annual; **W=Winter; +F = Fall; ++Sp=Spring;+++ S= Summer; \# NS = Not significant)

Run et al. (2007) introduction which the western Indian Himalayas found a $0.9^{\circ} \mathrm{C}$ rise obviously more than 100 yrs (1901 2003). They express a ton of this watched miracles is associated with shoot after 1972. Using wintertime (Dec Feb) month temperature information from 1975 to 2006, Dimri and Dash (2011) in like manner found a warming example over the western Indian Himalayas, with the most flawlessly awesome discovered extended Tmax $\left(1.12 .5^{\circ} \mathrm{C}\right)$. Over the northwest Indian Himalayan area, Bhutiyani et al. (2007) found $1.6{ }^{\circ} \mathrm{C}$ warming $\left(0.16^{\circ}\right.$ $\mathrm{C} /$ decade) inside the twentieth century. Singh et al. (2008) watched boosting designs in periodic Tmax and ordinary of consistently perfect temperature for most weeks beside storm over the lower Indus bowl in the northwest Indian Himalaya. Fowler and Archer (2005) report extending designs in winter temperature during 1961-2000 in the upper Indus bowl (Pakistan) with moving warming paces of 0.07-0.51 ${ }^{\circ} \mathrm{C} /$ decade in yearly mean temperature (Tav) and $0.1-0.55{ }^{\circ} \mathrm{C} /$ decade in Tmax. Extending most noteworthy winter heat inside the best Indus bowl had been found by Khattak et al. (2011) who found an extending warming arrangement of $0.45,0.42,0.23^{\circ} \mathrm{C} /$ decade in Tmax of the top, independently, constraining districts, focus, during 1967 to 2005[25].

\subsection{Spatial changeability in precipitation patterns}

In contrast to temperature, essentially all the composing articles a nonattendance of spatially normal stretch course in Himalayan rainfall. These nonappearances of homogeneity in designs reverse the effect of neighborhood thermodynamic and orographic processes [38] over huge scale sea climatic errands. Contrasts in precipitation way could furthermore be seen crosswise over seasons. In an as of late available investigation, Bhutiyani et al. (2010) watched a factually huge descending structure (at $5 \%$ criticalness level) in rainstorm and ordinary yearly precipitation in the Indian Himalaya during 1866 to 2006. A relative style is referenced for 1960 to 2006 over the western-Indian Himalaya region [39] however with no note of measurable hugeness. 
Rahul Malik et al.

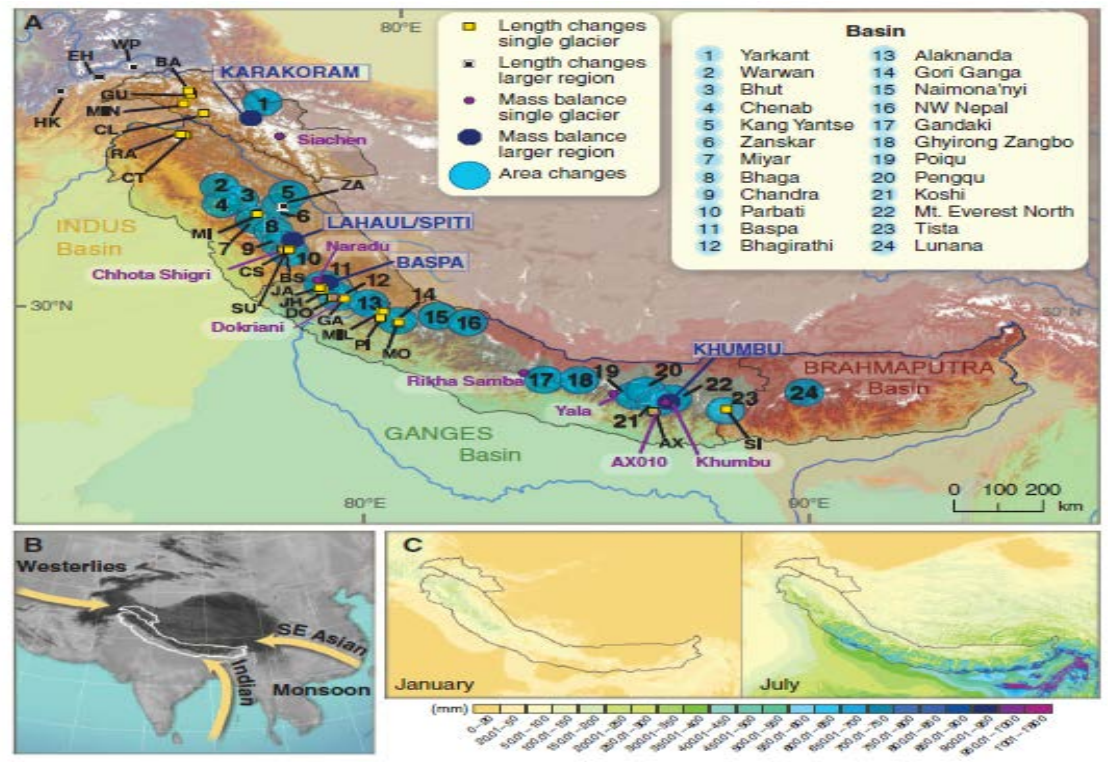

Figure 7. (A) Guide of Himalaya exhibiting the significant waterway bowls and furthermore the spots of determined costs of progress in region and of a trial of ice sheet length move just as mass accounts estimations. (B) Main blowing wind frameworks. (C) Mean precipitation in July and January[40].

The writing shows intra territorial differences in winter months precipitation prevailing fashions over Western-Indian Himalaya. Dimri and run (2011) note exceptionally winding down wintertime rainfall in the locale for 1975 to 2006 amidst nonattendance of spatially understandable stages among different stations. Guhathakurta and Rajeevan (2008) find really basic slipping movement in wintertime rainfall in Jammu and Kashmir and Uttarakhand during 1901to 2003. Albeit no way can be found during the more drawn out 18951999 period [41], in correlation, factually huge expanding way are found in winter rainfall during 1961 1999 in top of the Indus Basin. In unequivocally the indistinguishable bowl, Khattak et al. (2011) discover spatially sporadic and for the most part measurably minor occasional precipitation crazes during 1967 2005; be that as it may, they review more expanding than diminishing patterns. Increment in pre rainstorm (March May) precipitation is as yet found over the western Indian Himalaya during 1901to 2003.

As expressed before, real procedures affecting precipitation are progressed activating huge fluctuation in saw precipitation design. Spatial changeability in rainfall drifts in the Himalayas and typically expressed in the writing, the accompanying provisional ends could be drawn dependent on the assessed writing. First of all, yearly rainfall just as storm is creating in Jammu and Kashmir in spite of the fact that rainfall is diminishing in the western-Indian Himalayas [42]. By then, winter precipitation is reducing in the western Indian Himalaya in spite of the way that it is making in top bit of the Indus Basin. Finally, there are basically no spatially wise development in Nepal or Bhutan; ultimately, there exists an extending yearly rainfall in the Chinese Himalaya with YarlungZangbo River bowl showing upward example in yearly, winter, at that point essentially spring precipitation [43]. 


\section{Discussion and conclusions}

Evidence is accumulating that fossil fuel burning is setting weather, as projected by looking for projections which are exact to aid adaptation. ESMs estimation eco-friendly deviation, with discretised formulas describing earth System. Although unfortunately considerable variations can be found between them, very apt for precisely the same GHG focus scenarios, a planet research achievement will be the merge of ESM simulations. Adaptation planning is complicated by this particular debt of agreement. The concept what ESMs actually black boxes, pressures using sufficient researcher time for build, constantly, tries to comprehend their inner calculations, feedbacks, remotes as well as significantly device differences are distressed by brand - brand new appearance models,. Such an approach circumnavigates prevailing health related methods, just exactly where creating mathematical models should happen with understanding of parallel analytical. The Earth Product is incredibly challenging also as it's difficult to get the dimension reduction vital that you fix dominating tasks. We're experiencing this particular is likely to create weather research a terrific program utilizing ML strategies. This approach is, although, provisional on the innovation getting going on affectionately, selecting perhaps the ideal for every analysis problem, jointly a big gratitude of every basic assumptions implicit with them. A great deal of preexisting models are summarised by us, noting to link predominantly to certain areas of climate system. The phone call of ours is going well a great deal more and use ML techniques on the entirety of the Global System, analysing gridded datasets ensemble. The introduction of ML approaches is provided by us along with recommend three attainable uses by what method interconnectivity is probable complex; a UK substantial occasion, the' warming hiatus', and terrestrial setting equation developing. Furthermore, AI might utilise data-based and model- ML to offer alerts as well as help option help, for example during acquiring near extremes as droughts. The early morning accessibility of h20 information indicates that ML based research documents needs adequate clarity that others are pressed to replicate, and possibly check, using their private ML methods. In any other situations, the real ML coding may well also be created led to permit replication of outcomes. The original framework includes an enhanced and unbiased substantially check. The problem of reproducibility when as opposed with replicability, and also in an AI context, is analyzed in Drummond. To sum up, normal adoption of ML methods, that'll have various levels of achievement is advocated by a really terrific proposition of healthcare disciplines. We think ML plan on the Earth System is going to fall within the lucrative team, presuming you with extraordinary insights into the extremely abundant assortment of interconnected behaviors Earth System along with their numerous interactions with biochemical cycles. Although for water analysis we think it over being properly described, ai is truly, currently, a favorite phrase in contemporary society. While ML is going to reveal climate system attributes as well as enhanced forecasting according time scales, it's AI that might later comply with the info to guide choices. It's the instructing of procedures have to guarantee protection through setting extremes whereby ML gets AI. For significant green policy, embracing ML will most likely help the action switch should certainly achieve refined choices about the climatic us says anticipated for heightened GHG levels. 


\section{References}

[1] Chaturvedi R.K., Kulkarni A., KaryakarteY., Joshi J., Bala G., (2014), Glacial Mass Balance Changes in the Karakoram and Himalaya based on CMIP5 Multi-Model Climate Projections. Climatic Change, 2014, 315-328.

[2] A.V.Kulkarni., Glaciers as source of water: The Himalaya. Sustainable Humanity, Sustainable Nature: Our Responsibility, 2014.

[3] Sharma Kartik; Aggarwal Ashutosh; Singhania Tanay; Gupta Deepak; Khanna Ashish (2019). Hiding Data in Images Using Cryptography and Deep Neural Network. Journal of Artificial Intelligence and Systems, 1, 143-162.

[4] Raffaele Cioffi, Marta Travaglioni, Giuseppina Piscitelli, Antonella Petrillo and Fabio De Felice, Artificial Intelligence and Machine Learning Applications in Smart Production: Progress, Trends, and Directions, Sustainability 2020, 12, 492, 1-26.

[5] Levermann, A., P. U. Clark, B. Marzeion, G. A. Milne, D. Pollard, V. Radic, and A. Robinson, The multimillenial sea level commitment of global warming, Proc. Natl. Acad. Sci. U. S. A., 2013,110(3), 13745-13750.

[6] Tayal, Shresth, Climate Change Impacts on Himalayan Glaciers and Implications on Energy Security of India, TERI 2019: The Energy and Resources Institute, 1-32.

[7] Sousa, P. H. F.; Nascimento, N. M. M.; Almeida, J. S.; Rebouças Filho, P. P. and Albuquerque, V. H. C. (2019). Intelligent Incipient Fault Detection in Wind Turbines based on Industrial IoT Environment. Journal of Artificial Intelligence and Systems, 1, 1-19.

[8] Hongbo Duan, Gupeng Zhang, Shouyang Wangand Ying Fan, Robust climate change research: a review on multi-model analysis, Environ. Res. Lett. (14) 2019, 1-24.

[9] Aditya Khamparia, Gurinder Saini, Deepak Gupta, Ashish Khanna, Shrasti Tiwari, Victor Hugo C. de Albuquerque: Seasonal Crops Disease Prediction and Classification Using Deep Convolutional Encoder Network. CSSP 39(2): 818-836 (2020).

[10] J. M. Maurer, J. M. Schaefer, S. Rupper, A. Corley, Acceleration of ice loss across the Himalayas over the past 40 years. Sci. Adv. 5, eaav7266, 2019.

[11] A. Dehecq, N. Gourmelen, A. S. Gardner, F. Brun, D. Goldberg, P. W. Nienow, E. Berthier, C. Vincent, P. Wagnon, E. Trouvé, Twenty-first century glacier slowdown driven by mass loss in High Mountain Asia. Nat. Geosci., 2019, 12, 22-27.

[12] M. Begert, C. Frei, Long-term area-mean temperature series for Switzerland-Combining homogenized station data and high resolution grid data. Int. J. Climatol., 2018, 38, 2792-2807.

[13] Khamparia, A., Singh, A., Anand, D., Gupta, D., Khanna, A., Arun Kumar, N., \& Tan, J. , A novel deep learning-based multi-model ensemble method for the prediction of neuromuscular disorders. Neural Computing and Applications, 2018.

[14] K. Mukherjee, A. Bhattacharya, T. Pieczonka, S. Ghosh, T. Bolch, Glacier mass budget and climate reanalysis data indicate a climatic shift around 2000 in Lahaul-Spiti, western Himalaya. Clim. Change, 2018, 148, 219-233.

[15] M. F. Azam, P. Wagnon, E. Berthier, C. Vincent, K. Fujita, J. S. Kargel, Review of the status and mass changes of Himalayan-Karakoram glaciers. J. Glaciol., 2018, 64, 61-74. 
[16] Wu C, Chen Y, Peng C, Li Z and Hong X, Modeling and estimating aboveground biomass of Dacrydium pierrei in China using machine learning with climate change J. Environ. Manage, 2019, 234 167-79.

[17] Sharma, P., Gupta, A., Aggarwal, A., Gupta, D., Khanna, A., Hassanien, A. E., \& de Albuquerque, V. H. C., The health of things for classification of protein structure using improved grey wolf optimization. The Journal of Supercomputing, 2018.

[18] Aditi Mukherji, Anna Sinisalo, Marcus Nüsser, Rodney Garrard \& Mats Eriksson, Contributions of the cryosphere to mountain communities in the Hindu Kush Himalaya: a review, Regional Environmental Change, 2019 19:1311-1326.

[19] Huss M, Hock R, Global-scale hydrological response to future glacier mass loss. Nat Clim Chang, 2018, 8:135-140.

[20] Aditya Khamparia, Babita Pandey, Shrasti Tiwari, Deepak Gupta, Ashish Khanna, Joel J. P. C. Rodrigues: An Integrated Hybrid CNN-RNN Model for Visual Description and Generation of Captions. CSSP 39(2): 776-788 (2020).

[21] Lutz AF, Maat HW, Wijngaard RR, Biemans H, Syed A, Shrestha AB, Wester P, Immerzeel WW, 2018 South Asian river basins in a $1.5^{\circ} \mathrm{C}$ warmer world. Regional Environmental Change

[22] B R ARORA and RESOURCE TEAM, The Himalayan Cryosphere: Appraisal of Climate-Glacier Inter-linkages, Proc Indian Natn Sci Acad 85 No. 2 June 2019 pp. 319-342.

[23] Aditya Khamparia, Sagar Pande, Deepak Gupta, Ashish Khanna, Arun K. Sangaiah, Multilevel Framework for Anomaly Detection in Social Networking, Library Hi Tech (Emerald), 2019.

[24] Ajai, Inventory and Monitoring of Snow and Glaciers of the Himalaya using Space Data In: Science and Geopolitics of the white world Arctic, Antarctic and Himalaya (SaGAA) (Eds) P S Goel, Rasik Ravindra and Sulagna Chattopadhyay, 2018, pp101-130.

[25] Khan A A, Pant N C, Ravindra R, Alok A, Gupta M and Gupta S, A precipitation perspective of the Hydrospherecryosphere interaction in the Himalaya Geological Society London Special Publications, 2018, pp 462-473.

[26] Sachi Nandan Mohanty, K. C. Ramya, S. Sheeba Rani, Deepak Gupta, K. Shankar, S. K. Lakshmanaprabu, Ashish Khanna: An efficient Lightweight integrated Blockchain (ELIB) model for IoT security and privacy. Future Gener. Comput. Syst. 102: 1027-1037 (2020).

[27] Pant N C, Ravindra R, Srivastava D and Thompson L G (eds), The Himalayan Cryosphere: Past and Present. Geological Society, London, Special Publications, 2018, 462.

[28] Boers $\mathrm{N}$ et al., Complex networks reveal global pattern of extreme-rainfall remotes Nature, 2019, 566 373-77.

[29] Buckland C E, Bailey R M and Thomas D S G, Using artificial neural networks to predict future dryland responses to human and climate disturbances Sci. Rep., 2019, 93855.

[30] Akshi Kumar, Himanshu Ahuja, Nikhil Kumar Singh, Deepak Gupta, Ashish Khanna, Joel J. P. C. Rodrigues: Supported matrix factorization using distributed representations for personalised recommendations on twitter. Comput. Electr. Eng. 71: 569-577 (2018). 
[31] Ghiggi G, Humphrey V, Seneviratne S I and Gudmundsson L, GRUN: an observations-based global gridded runoff dataset from 1902 to 2014 Earth Syst. Sci. Data Discuss. 2019, 1-32.

[32] Germanno Teles, Joel J. P. C. Rodrigues, Ricardo A. L. Rabê, Sergei A. Kozlov (2020). Artificial neural network and Bayesian network models for credit risk prediction. Journal of Artificial Intelligence and Systems, 2, 118-132.

[33] Knusel B et al., Applying big data beyond small problems in climate research Nat. Clim. Change, 2019, 9 196-202.

[34] Kornhuber Ket al., Extreme weather events in early summer 2018 connected by a recurrent hemispheric wave-7 pattern Environ. Res. Lett., 2019, 14 054002.

[35] Anvita Saxena, Ashish Khanna, Deepak Gupta (2020). Emotion Recognition and Detection Methods: A Comprehensive Survey. Journal of Artificial Intelligence and Systems, 2, 53-79.

[36] Raissi M, Perdikaris P and Karniadakis G E, Physics-informed neural networks: a deep learning framework for solving forward and inverse problems involving nonlinear partial differential equationsJ. Comput. Phys., 2019, 378 686-707.

[37] Reichstein $\mathrm{M}$ et al., Deep learning and process understanding for data-driven Earth system science Nature, 2019, 566 195-204.

[38] Yang $\mathrm{H}$ et al., Strong but intermittent spatial covariations in tropical land temperature Geophys. Res. Lett., 201946 356-64.

[39] Ricardo Vinuesa, Hossein Azizpour Iolanda Leite, Madeline Balaam, Virginia Dignum, Sami Domisch, Anna Felländer , Simone Daniela Langhans, Max Tegmark \& Francesco Fuso Nerini, The role of artificial intelligence in achieving the Sustainable Development Goals, Nature Communications, 2020, 11:233.

[40] Kulkarni, A. V. and Suja Alex, Estimation of recent glacial variations in Baspa basin using remote sensing technique. Journal of Indian Society of Remote Sensing, 2003, 31(2), 81-90.

[41] Duan, Y.; Edwards, J.S.; Dwivedi, Y.K. Artificial intelligence for decision making in the era of Big Data—Evolution, challenges and research agenda. Int. J. Inf. Manag. 2019, 48, 63-71.

[42] Ngozi H. Arihilam, E. C. Arihilam, Impact and control of anthropogenic pollution on the ecosystem - A review, 54-59, 2019.

[43] Aditya Khamparia, Babita Pandey,Devendra Kr.Pandey,Deepak Gupta,Ashish Khanna, Victor Hugo Cde Albuquerque, Comparison of RSM, ANN and Fuzzy Logic for extraction of Oleonolic Acid from Ocimum sanctum, Volume 117, May 2020.

[44] Chouhan, V.; Singh, S.K.; Khamparia, A.; Gupta, D.; Tiwari, P.; Moreira, C.; Damaševičius, R.; de Albuquerque, V.H.C., A Novel Transfer Learning Based Approach for Pneumonia Detection in Chest X-ray Images. Appl. Sci., 10, 559, 2020.

[45] Huntingford, C., Jeffers, E. S., Bonsall, M. B., Christensen, H. M., Lees, T., and Yang, H.: Machine learning and artificial intelligence to aid climate change research and preparedness, Environ. Res. Lett., 14, 124007, https://doi.org/10.1088/1748-9326/ab4e55, 2019. 